\title{
Short- and long-term glucocorticoid treatment enhances insulin signalling in human subcutaneous adipose tissue
}

\author{
LL Gathercole, SA Morgan, IJ Bujalska, PM Stewart and JW Tomlinson
}

Centre for Endocrinology, Diabetes and Metabolism, School of Clinical and Experimental Medicine, Institute of Biomedical Research, University of Birmingham, Birmingham, UK

Background: Endogenous or exogenous glucocorticoid (GC) excess (Cushing's syndrome) is characterized by increased adiposity and insulin resistance. Although GCs cause global insulin resistance in vivo, we have previously shown that GCs are able to augment insulin action in human adipose tissue, contrasting with their action in skeletal muscle. Cushing's syndrome develops following chronic GC exposure and, in addition, is a state of hyperinsulinemia.

Objectives: We have therefore compared the impact of short- $(24 \mathrm{~h})$ and long-term (7 days) GC administration on insulin signalling in differentiated human adipocytes in the presence of low or high concentrations of insulin.

Results: Both short- $(24 \mathrm{~h})$ and long-term ( 7 days) treatment of chub-s7 cells with dexamethasone (Dex) (0.5 $\mu \mathrm{M})$ increased insulin-stimulated pTyr612IRS1 and pSer473akt/PKB, consistent with insulin sensitization. Chronic high-dose insulin treatment induced insulin resistance in chub-s7 cells. However, treatment with both high-dose insulin and Dex in combination still caused insulin sensitization.

Conclusions: In this human subcutaneous adipocyte cell line, prolonged GC exposure, even in the presence of high insulin concentrations, is able to cause insulin sensitization. We suggest that this is an important mechanism driving adipogenesis and contributes to the obese phenotype of patients with Cushing's syndrome.

Nutrition and Diabetes (2011) 1, e3; doi:10.1038/nutd.2010.3; published online 31 January 2011

Keywords: glucocorticoids; insulin signalling; obesity; cortisol; adipocyte

\section{Introduction}

The global epidemics of obesity and type 2 diabetes have heightened the need to understand the molecular mechanisms that contribute to their pathogenesis. Patients with Cushing's syndrome develop central obesity, insulin resistance and in some cases type 2 diabetes; this has focused attention on the potential pathogenic role of the hypothalamo-pituitary-adrenal axis, and endogenous glucocorticoid (GC) production and metabolism in simple obesity. Furthermore, the widespread therapeutic use of $\mathrm{GCs}^{1}$ means

Correspondence: Dr JW Tomlinson, Centre for Diabetes, Endocrinology and Metabolism, School of Clinical and Experimental Medicine, Institute of Biomedical Research, University of Birmingham, Edgbaston, Birmingham B15 2TT, UK.

E-mail. J.W.Tomlinson@bham.ac.uk

Received 28 September 2010; revised 17 November 2010; accepted 17 November 2010 that understanding the mechanisms that lead to their adverse event profile has a huge clinical relevance.

GCs cause global insulin resistance. ${ }^{2}$ However, there is increasing evidence to suggest that GCs may have tissuespecific effects on insulin action., ${ }^{3,4}$ We have shown that short-term $(24 \mathrm{~h})$ treatment with the synthetic GCs, dexamethasone (Dex) and cortisol, causes insulin sensitization in human adipose tissue, ${ }^{3}$ in cells cultured in the absence of insulin. Additionally, we have shown that this is functionally important and augments insulin-stimulated glucose uptake. $^{3}$ This contrasts with the induction of insulin resistance in skeletal muscle. ${ }^{5,6}$ Although these observations have contradicted the widely held dogma that GCs cause global 'pan-tissue' insulin resistance, it remains plausible that prolonged administration of GCs may have differing effects on insulin signalling. In addition, GC excess leads to hyperinsulinemia, ${ }^{7}$ which may further fuel insulin resistance, ${ }^{8}$ and high concentrations of insulin may modify the effect of GCs in adipose tissue. We have therefore determined the impact of short- and long-term GC treatment on 
insulin signalling in adipose tissue at differing insulin concentrations.

\section{Materials and methods}

\section{Chub-s7 cell line}

Proliferating chub-s7 cells were cultured in Dulbecco's MEM/Nutrient Mixture F-, DMEM-F12 (Sigma, Poole, UK) with 10\% FCS and seeded into 12-well plates and grown until confluent. Cells were differentiated in chemically defined DMEM-F12 media for 14 days. ${ }^{3}$ Differentiated chub-s7 cells were cultured in media (DMEM-F12) without additives for $24 \mathrm{~h}$. Cells were then incubated with either 5 or $50 \mathrm{nM}$ insulin, with or without $0.5 \mu \mathrm{M}$ Dex for either $24 \mathrm{~h}$ or 7 days. We have previously cultured cells without insulin in the presence and absence of Dex, ${ }^{3}$ and the purpose of this study was not only to examine the impact of longterm Dex treatment, but also to replicate an environment that more closely resembles the physiological situation and includes high insulin concentrations. In all cell culture experiments investigating insulin signalling cascade protein phosphorylation, and in order to activate the insulin signalling cascade, media was spiked with human insulin $\left(0.1 \mu \mathrm{g} \mathrm{ml}^{-1}\right.$, Sigma) for the final $15 \mathrm{~min}$ of the treatment period.

\section{RNA extraction, reverse transcription and real-time PCR}

Total RNA was extracted using the Tri-Reagent system and mRNA levels or target genes were determined using an ABI 7500 sequence real-time PCR detection system (Perkin-Elmer Applied Biosystems, Warrington, UK). 'Assay on demand' probes and primers (Perkin-Elmer Applied Biosystems) were used (18S ribosomal RNA pre-optimized control probe). ${ }^{9}$ Data were obtained as ct values ( $\mathrm{ct}=$ cycle number at which logarithmic PCR plots cross a calculated threshold line) and used to determine $\Delta \mathrm{ct}$ values $(\Delta \mathrm{ct}=$ (ct of the target gene)-(ct of the housekeeping gene)). Data are expressed as arbitrary units using the following transformation: expression $\left(=10^{4} \times\left(2^{-\Delta \mathrm{ct}}\right)\right.$ arbitrary units (AU). When used, fold changes were calculated using the following equation: fold increase $=2^{- \text {difference in }-\Delta \mathrm{ct}}$.

\section{Protein extraction and immunoblotting}

Soluble protein extraction and quantification was performed as previously reported. ${ }^{3}$ Fifteen micrograms of protein sample was resolved on a $12.5 \%$ SDS-PAGE gel and transferred onto a nitrocellulose membrane, Hybond ECL (GE Healthcare, Chalfont St Giles, UK). Primary (anti-PKB/akt, IRS 1 and IRS 2, Upstate, Dundee, UK; anti-pSer473akt/PKB, R\&D Systems, Abingdon, UK; anti-pTyr612IRS1, Biosource, Nivelle, Belgium) and secondary antibodies (Dako, Glostrop, UK) were used at a dilution of $1 / 1000$ as described previously. ${ }^{3}$ Membranes were re-probed for $\beta$-actin (antibody dilution 1/5000, Abcam plc, Cambridge, UK). Bands were quantified with Genesnap (Syngene, Cambridge, UK).

\section{Statistical analysis}

Where data were normally distributed, unpaired Student's $t$-test was used to compare single treatments with control. If normality tests failed, then non-parametric tests were used. One-way analysis of variance on ranks was used to compare multiple treatments, doses or times (SigmaStat 3.1, Systat Software Inc., Point Richmond, CA, USA). Statistical analysis on real-time PCR data was performed on mean $\Delta \mathrm{ct}$ values and not on fold changes.

\section{Results}

Short-term Dex treatment $(24 \mathrm{~h})$ and insulin signalling in chub-s7 cells

Dex $(24 \mathrm{~h}, 0.5 \mu \mathrm{M})$ increased IRS2 and PI3K mRNA expression in the presence of both 5 and $50 \mathrm{~nm}$ insulin (Table 1). Insulin-stimulated pTyr612IRS1 increased following Dex pre-treatment, but this was less marked in the presence of high-dose insulin. Total IRS1 protein levels were not altered (Figures 1a and b), but IRS2 protein was increased

Table 1 mRNA expression as measured by real-time PCR in chub-s7 cells treated with insulin (low $5 \mathrm{nM}$ or high $50 \mathrm{nM}$ dose) with or without Dex ( $0.5 \mu \mathrm{M}$ ) for either $24 \mathrm{~h}$ or 7 days

\begin{tabular}{|c|c|c|c|c|c|c|c|c|}
\hline \multirow[t]{3}{*}{ Gene } & \multicolumn{4}{|c|}{ Short-term $(24 h)$} & \multicolumn{4}{|c|}{ Long-term (7d) } \\
\hline & \multicolumn{2}{|c|}{5 nM Insulin } & \multicolumn{2}{|c|}{$50 \mathrm{~nm}$ Insulin } & \multicolumn{2}{|c|}{5 nM Insulin } & \multicolumn{2}{|c|}{$50 \mathrm{~nm}$ Insulin } \\
\hline & Control & $0.5 \mu \mathrm{M}$ Dex & Control & $0.5 \mu \mathrm{M}$ Dex & Control & $0.5 \mu \mathrm{M}$ Dex & Control & $0.5 \mu \mathrm{M}$ Dex \\
\hline FABP4 & $76.93 \pm 68.80$ & $89.66 \pm 50.43$ & $67.37 \pm 36.10$ & $110.72 \pm 63.02$ & $52.86 \pm 17.24$ & $124.00 \pm 15.17$ & $47.90 \pm 24.31$ & $150.92 \pm 22.39^{\mathrm{a}}$ \\
\hline IRS-1 & $0.28 \pm 0.09$ & $0.47 \pm 0.17$ & $0.45 \pm 0.04$ & $0.48 \pm 0.03$ & $0.46 \pm 0.06$ & $0.62 \pm 0.12$ & $0.39 \pm 0.09$ & $0.57 \pm 0.14$ \\
\hline IRS-2 & $0.59 \pm 0.19$ & $1.61 \pm 0.49^{a}$ & $0.79 \pm 0.18$ & $2.53 \pm 0.26^{a}$ & $0.70 \pm 0.09$ & $2.08 \pm 0.40^{\mathrm{a}}$ & $1.19 \pm 0.26$ & $2.11 \pm \pm 0.43^{a}$ \\
\hline $\mathrm{PI3K}$ & $0.88 \pm 0.19$ & $2.87 \pm 0.85^{a}$ & $1.38 \pm 0.27$ & $4.73 \pm 0.68^{b}$ & $1.48 \pm 0.14$ & $5.84 \pm 1.69^{a}$ & $1.72 \pm 0.52$ & $6.56 \pm 1.87^{\mathrm{b}}$ \\
\hline AKT-1 & $2.51 \pm 0.88$ & $1.51 \pm 0.27$ & $1.77 \pm 0.38$ & $1.98 \pm 0.48$ & $1.22 \pm 0.39$ & $1.58 \pm 0.35$ & $1.61 \pm 0.34$ & $1.58 \pm 0.32$ \\
\hline AKT-2 & $0.85 \pm 0.22$ & $0.49 \pm 0.15$ & $0.85 \pm 0.18$ & $0.57 \pm 0.14$ & $0.70 \pm 0.36$ & $0.65 \pm 0.24$ & $0.62 \pm 0.13$ & $0.80 \pm 0.18$ \\
\hline
\end{tabular}

Abbreviations: d, days; Dex, dexamethasone. ${ }^{\mathrm{a}} P<0.05$. ${ }^{\mathrm{b}} \mathrm{P}<0.01$ vs control. Data are presented as mean arbitrary units \pm s.e. from $n=3-5$ experiments, with lower values representing higher mRNA expression. 
a

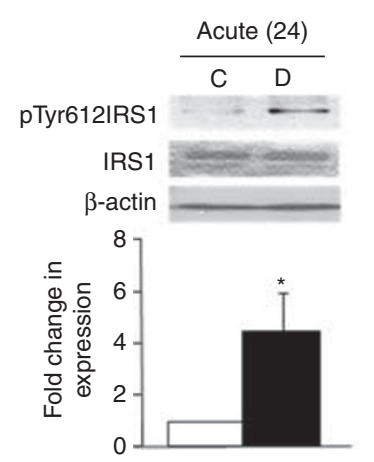

C
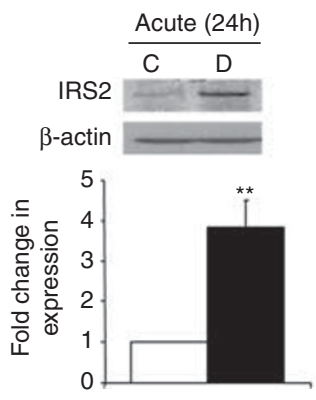

e
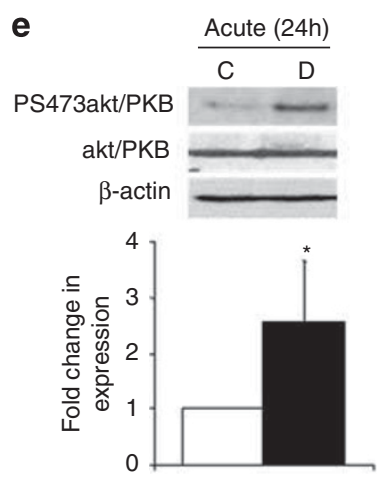

Insulin 5nM
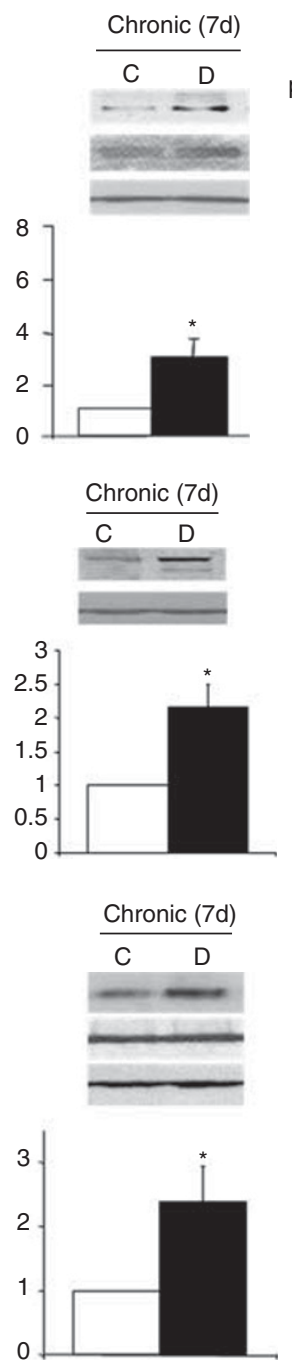

b

Insulin 50nM

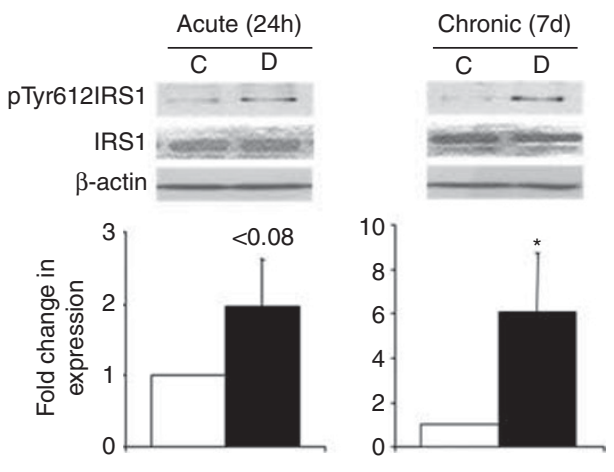

d
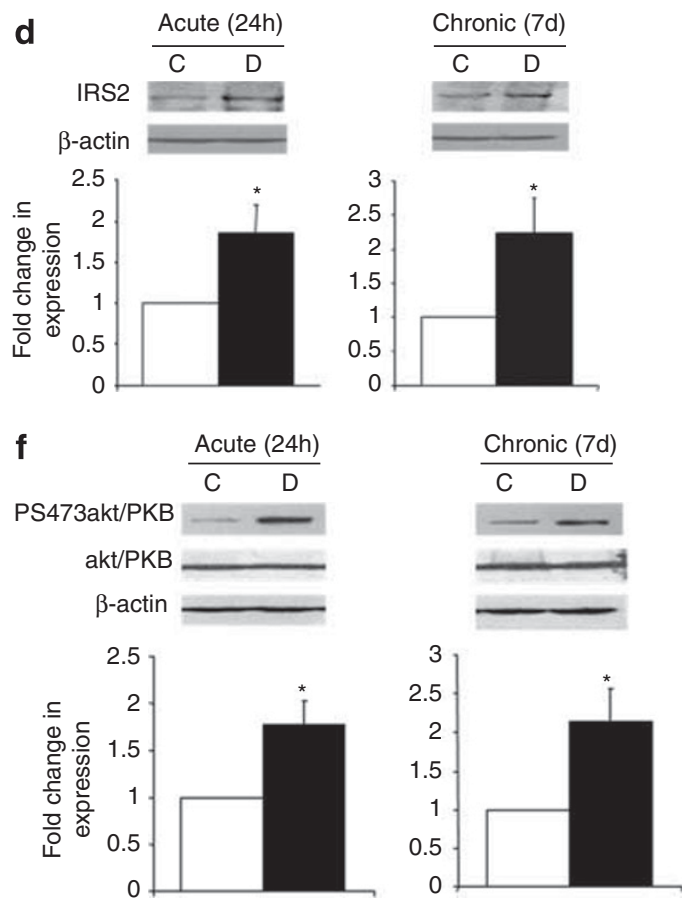

Figure 1 The effect of short- $(24 \mathrm{~h})$ and long-term ( 7 days) treatment of differentiated chub-s7 cells with dexamethasone (D, $0.5 \mu \mathrm{M})$ on insulin-stimulated activation of the insulin signalling cascade: (a, b) IRS1 and p612TyrIRS1; (c, d) IRS2; (e, f) akt/PKB and pSer473akt/PKB. Cells were co-incubated with either low insulin ( $5 \mathrm{nM})(\mathbf{a}, \mathbf{c}, \mathbf{e})$ or high insulin $(50 \mathrm{nM})(\mathbf{b}, \mathbf{d}, \mathbf{f})$ concentrations. Graphs shown are the mean of $n=3-5$ experiments \pm s.e., with western blots quantified against $\beta$-actin; representative western blots are shown inserted $\left({ }^{*} P<0.05,{ }^{*} P<0.01\right.$ vs control; white bars $=$ control $(C)$ and black bars $=$ dexamethasone $\left.(D)\right)$.

(Figures 1c and d). Further downstream, Dex treatment for $24 \mathrm{~h}$ increased insulin-stimulated pS473akt/PKB, with no alteration in total akt/PKB levels in the presence of either 5 or $50 \mathrm{~nm}$ insulin (Figures $1 \mathrm{e}$ and $\mathrm{f}$ ). In cells that were not spiked with insulin to activate the insulin signalling, Dex pretreatment alone did not alter IRS1 or akt/PKB phosphorylation.

Long-term Dex treatment (7 days) and insulin signalling in chub-s7 cells

Only in the presence of high-dose insulin (50 nM) did Dex increase FABP4 mRNA expression (Table 1). Seven-day Dex treatment increased IRS2 and PI3K mRNA expression in the presence of both 5 and $50 \mathrm{~nm}$ insulin (Table 1).
Insulin-stimulated pTyr612IRS1 levels increased following Dex pre-treatment at both doses of insulin (5 and $50 \mathrm{nM}$ ), but total IRS1 protein levels did not change (Figures $1 \mathrm{a}$ and $\mathrm{b}$ ). However, 7 days treatment with Dex increased IRS2 protein levels (Figures 1c and d). Insulin-stimulated pS473akt/PKB in the presence of either 5 or $50 \mathrm{nM}$ insulin increased following chronic Dex treatment, without changing the total akt/PKB protein levels (Figures 1e and f).

Insulin treatment and insulin signalling in chub-s7 cells Although not the major purpose of the study, we were able to compare the effects of 5 and $50 \mathrm{~nm}$ insulin pre-treatment and the duration of pre-treatment on the ability of insulin to 
a

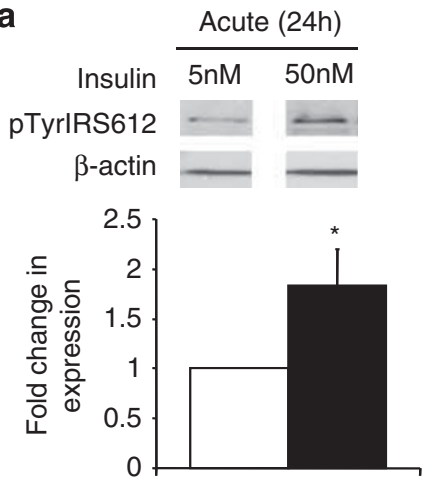

b
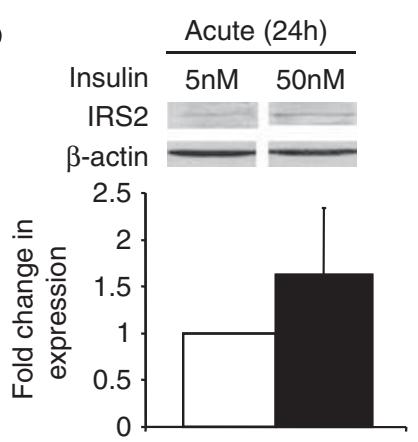

C
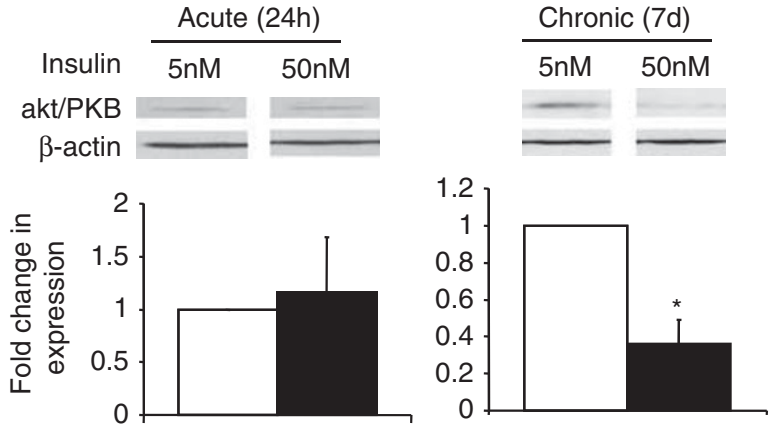

Figure 2 Insulin treatment does not effect IRS2 expression in chub-s7 cells (a). In comparison with $5 \mathrm{nM}$ insulin, treatment with $50 \mathrm{nM}$ insulin for $24 \mathrm{~h}$ enhances insulin-stimulated pTyr612IRS1 expression (b), but prolonged (7-day) insulin treatment decreases insulin-stimulated pTyr612IRS1 (b) and total akt/PKB expression (c). Graphs shown are the mean of $n=3-5$ experiments \pm s.e. and western blots quantified against $\beta$-actin; representative western blots are shown above. ${ }^{*} P<0.05$, ${ }^{* *} P<0.01$ (white bars represent low-dose insulin, and black bars high-dose insulin).

activate the insulin signalling cascade. Basal samples without any additives were not available for comparison, but have been reported previously. ${ }^{3}$

In comparison with $24 \mathrm{~h}$ treatment, 7-day exposure to $5 \mathrm{nM}$ insulin increased PI3K expression, but decreased akt1/PKB expression. There were no significant differences in gene expression between cells treated with $50 \mathrm{~nm}$ insulin for either $24 \mathrm{~h}$ or 7 days (Table 1 ).

Chronic exposure to high doses of insulin is known to cause insulin resistance. In agreement with this, 7 days (as compared with $24 \mathrm{~h}$ ) treatment with high-dose insulin (50 nM) decreased insulin-stimulated pTyr612IRS1 and
akt/PKB protein levels without changing total IRS2 protein expression (Figure 2).

\section{Discussion}

We have demonstrated that both short-term $(24 \mathrm{~h})$ and prolonged (7 days) treatment with GCs have similar effects on insulin action. In both situations, GCs cause insulin sensitization, as evidenced by enhanced insulin-stimulated pTyr612IRS1 and pS473akt/PKB levels, without altering total IRS1 or akt/PKB expression. Also, IRS2 mRNA and protein expression increased.

The effects of GCs on the adipose tissue are complex. Although they promote adipocyte differentiation, ${ }^{10}$ they also drive lipolysis. ${ }^{11}$ The impact of GCs on insulin signalling has only been studied in a small number of studies using human models. In omental cells, GCs decrease insulinstimulated glucose uptake, but are without effect in subcutaneous (s.c.) cells. ${ }^{12}$ However, detailed analysis of the insulin signalling cascade was not performed in this study. We have shown that GCs enhance insulin signalling in a human s.c. cell line and in primary cultures of human s.c. adipocytes, and that insulin-stimulated glucose uptake is enhanced by GC pre-treatment. ${ }^{3}$ More recently, studies endorsing our published data have shown that Dex treatment ( $48 \mathrm{~h}$ only) in human isolated pre-adipocytes causes insulin sensitization with increased IRS1 and akt/PKB phosphorylation. ${ }^{4}$ Our data extend these findings and suggest that chronic GC exposure (7 days) is also able to insulin-sensitize human adipose tissue. However, there are limitations with the models that have been used. In our own studies, we have used an immortalized human s.c. adipocyte cell line. In previous papers differentiated cultured adipocytes have been used, and in others intact isolated adipocytes. All these different methodologies can make data difficult to interpret; however, there still appears to be an emerging consensus that GCs, far from causing insulin resistance in adipose tissue, may actually cause insulin sensitization. A further important caveat is that these are systems examined in isolation and clinical studies are needed to determine the impact of GCs on insulin action in human adipose tissue in vivo.

Species specificity of response is likely to underpin the discrepancy in observations between rodent models and human studies. Rodent models have demonstrated GC-induced insulin resistance in adipose tissue. ${ }^{4,13,14}$ However, rodents do not develop the classic Cushing's phenotype that is observed in humans in response to GC administration, and indeed can suffer from weight loss. ${ }^{15}$

The results of our study add weight to the body of evidence supporting tissue-specific and species-specific regulation of insulin action by GCs. The precise molecular mechanisms remain to be determined. GCs regulate FoxO1A and FoxO3A in rodents and humans, ${ }^{16,17}$ and it has been suggested that the GC induction of these transcription factors may lead 
to increased IRS1 expression. ${ }^{4}$ However, we observed no increases in IRS1 mRNA or protein expression even after 7 days of GC treatment. We did not examine expression levels of FoxO1A or FoxO3A. A consistent finding across many studies is GC induction of IRS2. ${ }^{3-5,17}$ This occurs in adipose tissue (cell lines, primary cultures, and in both s.c.and omental depots) and skeletal muscle, but is not a consistent finding in rodents. ${ }^{18}$ Although in some tissues this may be a compensatory mechanism to try to augment insulin signalling in the face of insulin resistance, in human adipose tissue it represents an additional mechanism by which GCs enhance insulin signalling.

Cushing's syndrome is a state of hyperinsulinemia, ${ }^{7}$ and high insulin concentrations are a cause of insulin resistance; ${ }^{8,19,20}$ Our data endorse this in human adipose tissue. Chronic insulin treatment causes phosphorylation of IRS1 at a number of serine residues (including serine 302, 307, 612 and 623; rat numbering) and inhibits function. ${ }^{8,20}$ The aim of our study was not to look specifically at the effect of insulin administration on specific phosphorylation patterns; however, in our chub-s7 model, 7-day administration of high-dose insulin $(50 \mathrm{nM})$ did induce insulin resistance. When we incubated GCs with both 50 and $5 \mathrm{~nm}$ insulin (concentrations that are probably in excess of those seen in patients with Cushing's syndrome), we still observed insulin sensitization, suggesting that, in human adipose tissue, the impact of GC treatment is able to overcome the insulininduced insulin resistance.

Our observations are relevant to patients with Cushing's syndrome. GC-induced adipose tissue insulin sensitization, even in the context of hyperinsulinaemia, will further enhance adipocyte differentiation and lipid accumulation. The depot specificity of action in human adipose tissue remains an important and unanswered question. Patients with Cushing's syndrome develop more marked central adiposity, although s.c. fat mass also increases. ${ }^{21}$ Our observations offer an explanation for the increase in s.c. adiposity associated with GC excess. Further investigations to determine the precise molecular events underpinning the tissue specificity of response are now warranted. A better understanding of these mechanisms raises the prospect for the development of novel classes of GC that are therapeutically efficacious, but do not drive adiposity.

\section{Conflict of interest}

The authors declare no conflict of interest.

\section{Acknowledgements}

Funding for this study has been provided by the MRC (senior clinical fellowship to JWT) and by the WellcomeTrust (programme grant to PMS). We would like to thank Dr C Darimont (Nestle, Switzerland) for providing the chub-s7 cells.

\section{References}

1 Van Staa TP, Leufkens HG, Abenhaim L, Begaud B, Zhang B, Cooper C. Use of oral corticosteroids in the United Kingdom. QJM 2000; 93/2: 105-111.

2 Larsson H, Ahren B. Short-term dexamethasone treatment increases plasma leptin independently of changes in insulin sensitivity in healthy women. J Clin Endocrinol Metab 1996; 81/12: 4428-4432.

3 Gathercole LL, Bujalska IJ, Stewart PM, Tomlinson JW. Glucocorticoid modulation of insulin signaling in human subcutaneous adipose tissue. J Clin Endocrinol Metab 2007; 92/11: 4332-4339.

4 Tomlinson JJ, Boudreau A, Wu D, Abdou SH, Carrigan A, Gagnon A et al. Insulin sensitization of human preadipocytes through glucocorticoid hormone induction of forkhead transcription factors. Mol Endocrinol 2010; 24/1: 104-113.

5 Morgan SA, Sherlock M, Gathercole LL, Lavery GG, Lenaghan C, Bujalska IJ et al. 11\{beta\}-hydroxysteroid dehydrogenase type 1 regulates glucocorticoid-induced insulin resistance in skeletal muscle. Diabetes 2009; 58: 2506-2515.

6 Saad MJ, Folli F, Kahn JA, Kahn CR. Modulation of insulin receptor, insulin receptor substrate-1, and phosphatidylinositol 3-kinase in liver and muscle of dexamethasone-treated rats. J Clin Invest 1993; 92/4: 2065-2072.

7 Nosadini R, Del PS, Tiengo A, Valerio A, Muggeo M, Opocher G et al. Insulin resistance in Cushing's syndrome. J Clin Endocrinol Metab 1983; 57/3: 529-536.

8 Rui L, Aguirre V, Kim JK, Shulman GI, Lee A, Corbould A et al. Insulin/IGF-1 and TNF-alpha stimulate phosphorylation of IRS-1 at inhibitory Ser307 via distinct pathways. J Clin Invest 2001; 107/2: 181-189.

9 Bujalska IJ, Gathercole LL, Tomlinson JW, Darimont C, Ermolieff J, Fanjul AN et al. A novel selective 11beta-hydroxysteroid dehydrogenase type 1 inhibitor prevents human adipogenesis. J Endocrinol 2008; 197/2: 297-307.

10 Hauner H, Schmid P, Pfeiffer EF. Glucocorticoids and insulin promote the differentiation of human adipocyte precursor cells into fat cells. J Clin Endocrinol Metab 1987; 64/4: 832-835.

11 Lundgren M, Buren J, Lindgren P, Myrnas T, Ruge T, Eriksson JW. Sex- and depot-specific lipolysis regulation in human adipocytes: interplay between adrenergic stimulation and glucocorticoids. Horm Metab Res 2008; 40: 854-860.

12 Lundgren M, Buren J, Ruge T, Myrnas T, Eriksson JW. Glucocorticoids down-regulate glucose uptake capacity and insulinsignaling proteins in omental but not subcutaneous human adipocytes. J Clin Endocrinol Metab 2004; 89/6: 2989-2997.

13 Buren J, Liu HX, Jensen J, Eriksson JW. Dexamethasone impairs insulin signalling and glucose transport by depletion of insulin receptor substrate-1, phosphatidylinositol 3-kinase and protein kinase B in primary cultured rat adipocytes. Eur J Endocrinol 2002; 146/3: 419-429.

14 Buren J, Lai YC, Lundgren M, Eriksson JW, Jensen J. Insulin action and signalling in fat and muscle from dexamethasone-treated rats. Arch Biochem Biophys 2008; 474/1: 91-101.

15 Tonolo G, Fraser R, Connell JM, Kenyon CJ. Chronic low-dose infusions of dexamethasone in rats: effects on blood pressure, body weight and plasma atrial natriuretic peptide. J Hypertens 1988; 6/1: 25-31.

16 Waddell DS, Baehr LM, van den Brandt J, Johnsen SA, Reichardt HM, Furlow JD et al. The glucocorticoid receptor and FOXO1 synergistically activate the skeletal muscle atrophy-associated MuRF1 gene. Am J Physiol Endocrinol Metab 2008; 295/4: E785-E797.

17 Bujalska IJ, Quinkler M, Tomlinson JW, Montague CT, Smith DM, Stewart PM. Expression profiling of 11beta-hydroxysteroid dehydrogenase type-1 and glucocorticoid-target genes in subcutaneous and omental human preadipocytes. $J$ Mol Endocrinol 2006; 37/2: 327-340. 
18 Zheng B, Ohkawa S, Li H, Roberts-Wilson TK, Price SR. FOXO3a mediates signaling crosstalk that coordinates ubiquitin and atrogin-1/MAFbx expression during glucocorticoid-induced skeletal muscle atrophy. FASEB J 2010; 24: 2660-2669.

19 Werner ED, Lee J, Hansen L, Yuan M, Shoelson SE. Insulin resistance due to phosphorylation of insulin receptor substrate-1 at serine 302. J Biol Chem 2004; 279/34: 35298-35305.

20 Gual P, Gremeaux T, Gonzalez T, Le Marchand-Brustel Y, Tanti JF. MAP kinases and mTOR mediate insulin-induced phosphorylation of insulin receptor substrate-1 on serine residues 307, 612 and 632. Diabetologia 2003; 46/11: 1532-1542.
21 Mayo-Smith W, Hayes CW, Biller BM, Klibanski A, Rosenthal $\mathrm{H}_{\text {, }}$ Rosenthal DI. Body fat distribution measured with CT: correlations in healthy subjects, patients with anorexia nervosa, and patients with Cushing syndrome. Radiology 1989; 170/2: 515-518.

This work is licensed under the Creative Commons Attribution-NonCommercial-No Derivative Works 3.0 Unported License. To view a copy of this license, visit http://creativecommons.org/ licenses/by-nc-nd/3.0/ 